\title{
Precision Prediction of Knitted Fabric Loop Length Through Online Monitoring of Yarn Input Tension and Course Length-A Mathematical Approach for Circular Weft Knitting With Positive Storage Feeding
}

\author{
A.K.M. Mobarok Hossain \\ Department of Textile Engineering, Ahsanullah University of Science and \\ Technology, Dhaka, Bangladesh
}

Dr. Abu Rayhan Md. Ali

Department of Mechanical Engineering, Bangladesh University of Engineering and Technology, Dhaka, Bangladesh

Doi: 10.19044/esj.2017.v13n30p463 URL:http://dx.doi.org/10.19044/esj.2017.v13n30p463

\begin{abstract}
A model in the form of an equation has been developed based on the mechanical consideration of yarn during dynamic circular weft knitting process that runs with positive storage feed system. The predicted course length through this model has been compared with that found from actual fabric by a recognized apparatus, i.e. HATRA Course Length Tester. The ttest was carried out over the obtained results for statistical analysis purpose. It was observed that for spun polyester knitted fabric, as used in the experimental part, the model worked very effectively through precision prediction by showing very low average mean difference in predicted course length from that measured from the actual fabric. The $t$-values and corresponding p-values proved the difference between the predicted and actual results statistically significant and thus opened the scope for further investigation and calibration.
\end{abstract}

Keywords: Knitted fabric, Loop length, True Specific stress, Initial Modulus, Course Length Tester

\section{Introduction}

Knitting may be considered as a mechanical process in which yarn loops are interlocked to form fabric. Superior fabric quality like comfort and form-fitting are core reasons for the popularity of knitted fabrics. Circular weft knitting is the most widely practiced technique for knitted fabric formation where a circular needle-bed knitting machine is deployed to 
produce tubular fabric through weft wise yarn insertion.

A Knitted fabric manufacturer has to ensure some quality parameters like areal density usually expressed as gram per square meter (GSM), shrinkage etc. at desired level through controlling of some knitting variables. Among these variables loop length (Length of yarn in a single loop) acts as the single most important construction variable, which is generally measured from course length as shown in the following equation

$$
\mathrm{l}=\frac{\mathrm{C}}{\mathrm{N}}
$$

where 1 is the loop length, $\mathrm{C}$ indicates course length and $\mathrm{N}$ stands for number of needles knitting.

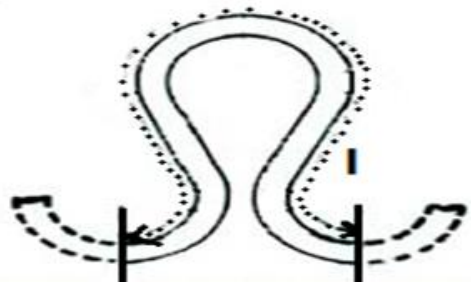

Figure 1: An Ideal Loop

Course length is generally measured by some online monitoring tool like yarn length meter during the machine running state. To maintain uniform and predetermined amount of yarn consumption per cylinder revolution, i.e. course length, positive storage feed systems are generally integrated with modern circular weft knitting machines. However, the actual stitch length found in the relaxed fabric through off-machine measurement by Course Length Tester or Crimp Tester generally deviates from that measured through online (Abou-iiana, 2000). Tensile force in running yarn causing yarn extension is the key reason for such deviation if the feed system functions flawlessly(Dias \& Lanarolle, 2002). Due to some practical limitations like fabric destruction (Ray, 2013) and high time consumption, off-machine measurement of course length is generally not preferred by a knitter during the dynamic knitting process. But still precision measurement of loop length is highly desired by the manufacturer to meet buyer's quality requirement at marginal tolerance as well as to save production cost. It was observed that a positive change in stitch length by $0.01 \mathrm{~mm}$ results in a negative change in areal density by approximately $1.00 \mathrm{~g} / \mathrm{m}^{2}$ in the cotton knitted fabric (Hossain \& Hoque, 2013).

It will, therefore, be highly welcomed by the manufacturers if the actual course length value can be predicted through online measurement as it is nondestructive and instant measurement is possible here. A careful observation on yarn tension and its influence on yarn length should act as the key guideline to this approach. 
The objective of this study is to evaluate yarn tension and the corresponding influence on yarn elongation during the continuous knitting process and thereafter establishing a mathematical model which can be universally applied to calculate actual course length of the knitted fabric from dynamic knitting parameters.

\section{Mechanical Considerations:}

Yarn

Yarn may be defined as linear assemblage of fibers or filaments formed into a one dimensional continuous strand having good tensile strength and high flexibility (Goswami, Martindale, \& Scardino, 1977). Generally yarn shows viscoelastic behavior which may be considered as linear type. During selected periods of progressive loading yarn shows spring-like behavior. During other periods of loading a creep type of deformation occurs (Adanur, 1995). As shown in figure 2, for a typical polyester fibre or yarn, $\mathrm{A}$ is the proportional limit, $\mathrm{OA}$ is the elastic region, $\mathrm{AB}$ is the viscoelastic region, $\mathrm{BC}$ is the stiffening region, $\mathrm{CD}$ is the second flow region and $\mathrm{D}$ is the breaking point. A viscoelastic yarn is thus assumed to show linear elastic behavior if the applied force does not exceed the proportional limit.

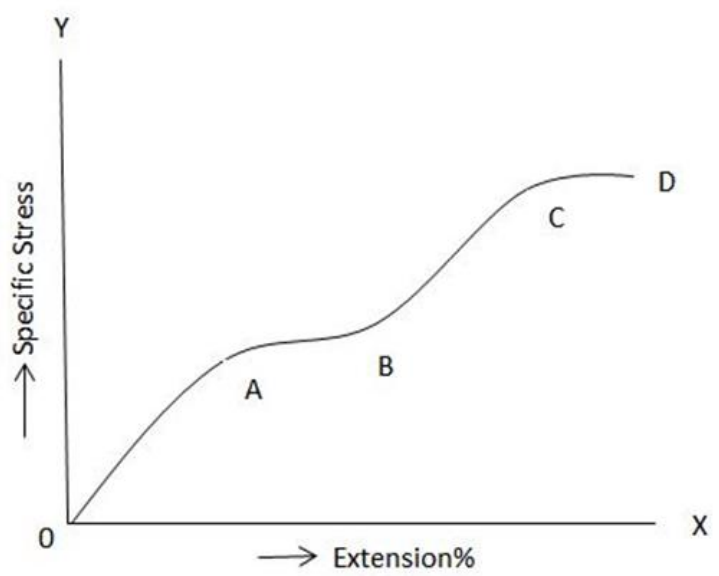

Figure 2: A typical polyester stress-strain diagram (Adanur, 1995).

\section{Yarn tension during knitting}

Tension zones are found throughout the yarn path as the yarn passes from package to creel, then to feed system and afterwards into the knitting needles. Yarn input tension (YIT) is the key concern to a knitter as yarn is delivered from the feed device to the knitting zone under this tension. As the loop formation procedure results increase and decrease of the yarn tensile force due to the knitting action of needles, YIT resembles a sinusoidal 
waveform that can be obtained through production monitoring system like Knitlab (Catarino, Rocha, \& Monteiro, 2003) or MLT Wesco PC Software as shown in figure 3.

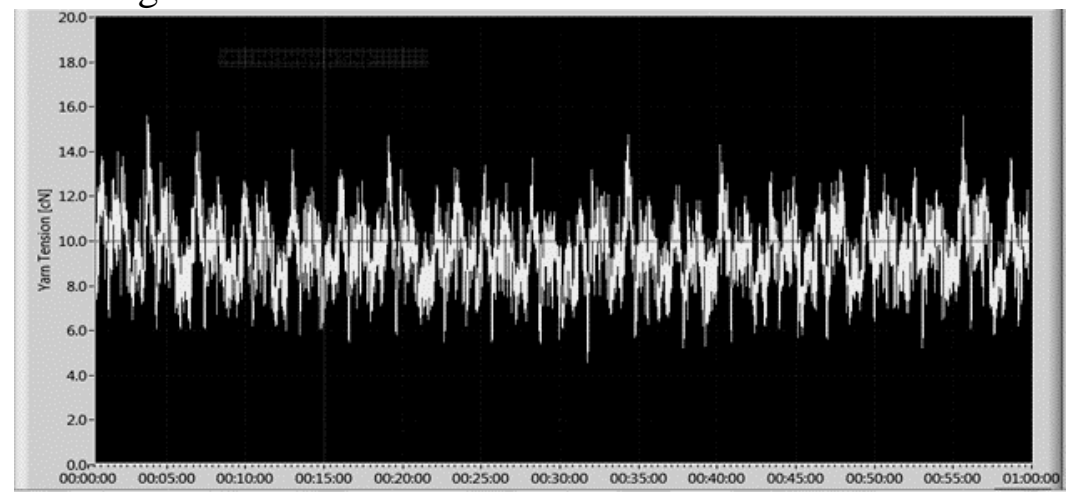

Figure 3: A typical YIT waveform during knitting

The corresponding stress, when a needle proceeds through the knitting cycle to form a loop, can be written as

$$
\sigma(\mathrm{t})=\sigma_{0} \sin (\omega \mathrm{t})
$$

Where $\sigma$ is the stress at time $t, \sigma_{0}$ is the maximum stress and $\omega$ is the circular frequency of stress change. As yarn input tension is maintained as low as possible for smooth knitting process, generally $\sigma$ and corresponding strain, $\varepsilon$ lie in the linear region of yarn's stress-strain curve. So strain can be written as

$$
\varepsilon(\mathrm{t})=\mathrm{E} \varepsilon_{0} \sin (\omega \mathrm{t})
$$

Where $\mathrm{E}$ is the initial modulus (young's modulus) of yarn and $\varepsilon_{0}$ is the corresponding strain for $\sigma_{0}$. Thus ignoring any loss of modulus at dynamic knitting condition and taking into account other marginal tension influencing factors it may be understood that average YIT measured online may be applied to calculate corresponding yarn elongation using basic law of elasticity.

\section{Actual course length measurement from fabric by the application of preload}

Course length measurement is done by determining the length of an unrove course slightly tensioned by a small load. The role of this tension is to straighten the yarn without stretching. Precision selection of the tension load is quite difficult as it is rarely possible to remove all the kinks before the yarn itself begins to stretch (Booth, 1986). Researchers used different regulatory preloads for course length or loop length measurements, either dependent on yarn linear density or fixed, as discussed by Pavko-Cuden and Sluga (2015). 
HATRA Course Length Tester is the most widely used equipment for off-machine measurement of course length. The equipment generally works with a preload of $10 \mathrm{cN}$ (for staple/spun yarn of up to 65Tex) in accordance with BS 5441(British Standards Institute, 1988) and has been recommended by many authors and researchers (Pavko-Cuden and Sluga, 2015).

\section{Assumptions:}

In order to formulate a mathematical model for actual course length the following assumptions are set up:

(1) Linear density and elastic performance coefficient of yarn remain constant throughout the yarn path during knitting operation.

(2) Tension peak observed during yarn feeding does not exceed the proportional limit.

(3) High build-up of knitting tension (tension of yarn inside the knitting zone) is compensated by the robbing-back so that any permanent deformation in yarn may be ignored.

(4) Influence of yarn unwinding tension from package and fabric takedown tension on yarn mechanical property, are all ignored.

\section{Model Development:}

Textile yarns generally have good extensibility and some yarns like stretch yarns may elongate two or more times of the original length and show quite full recovery when the force is released (Mishra, 2000). So formulating a model through true stress-true strain would be more universal considering the response of yarn to external force. It is very much convenient to use YIT (as shown in figure 4) for the model purpose as it can easily be adjusted and monitored by a knitter.

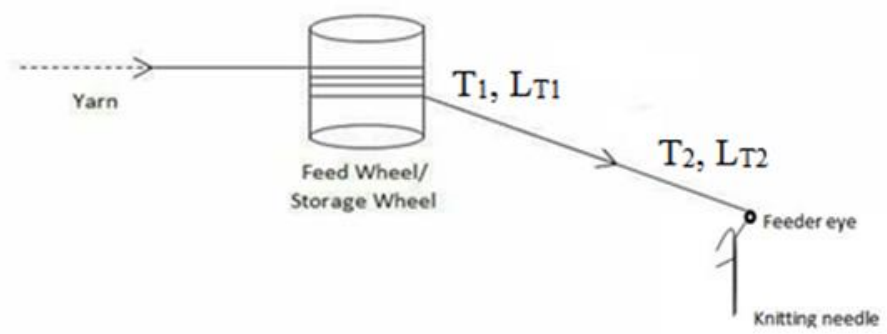

Figure 4: A simplified diagram of Yarn withdrawal and delivery through positive storage feed system in circular weft knitting. 
Let,

$\mathrm{T}_{1}=$ A particular value of average yarn input tension measured on the yarn path during the dynamic knitting process

$\mathrm{L}_{\mathrm{T} 1}=$ Length of yarn delivered to the knitting zone per cylinder revolution at tension T1

$\mathrm{T}_{2}=$ Yarn tension (other than $\mathrm{T}_{1}$ ) measured on the yarn path during the dynamic knitting process

$\mathrm{L}_{\mathrm{T} 2}=$ Length of yarn delivered to the knitting zone per cylinder revolution at tension $\mathrm{T}_{2}$

$\mathrm{L}_{0}=$ Course length $=$ Actual length of yarn in a course on a relaxed fabric $=$ Relaxed form (in length) of $\mathrm{L}_{\mathrm{T} 1}$ or $\mathrm{L}_{\mathrm{T} 2}$.

$\mathrm{t}=$ Yarn linear density, i.e. mass per unit length

Textile materials like yarns and fabrics contain unknown amount of space as well as fibres in their cross-sections. Therefore cross-sectional area of a yarn is not clearly defined and more useful measurement of stress is specific stress which is defined as the ratio of force to the linear density (Saville, 1999)

$$
\text { specific stress, } \sigma=\frac{T}{t}
$$

Thus considering yarn as a one-dimensional element it may be found that,

$$
\begin{aligned}
& \sigma_{\mathrm{T} 1}=\frac{T_{1}}{t} . \\
& \sigma_{\mathrm{T} 2}=\frac{T_{2}}{t} .
\end{aligned}
$$

As yarns are identified as fibrous and flexible material with greater extensibility, measurement of true stress and true strain on yarn give more meaningful values than engineering stress and strain as shown in figure 5 .

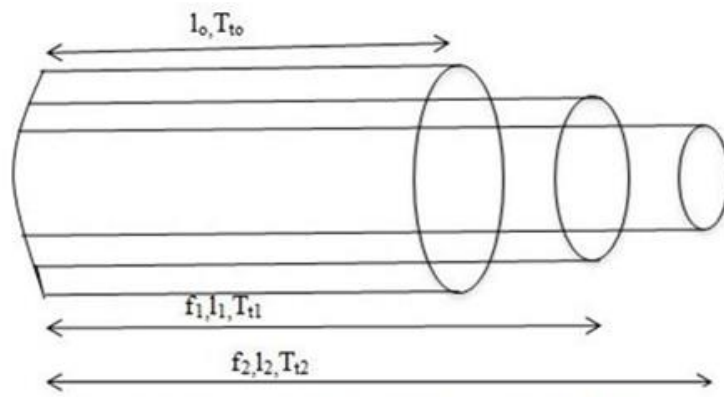

Mass of yarn segment (unstretched or stretched), $m=l_{o} T_{t o}=l_{l} T_{t 1}=l_{2} T_{t 2}$

Here,

$l_{o}=$ Unstretched length of a yarn segment

$T_{\text {to }}=$ Mass per unit length for $l_{o}$

$T_{t l}=$ Mass per unit length for stretched yarn segment $l_{1}$ at axial force $f_{1}$

$T_{t 2}=$ Mass per unit length for stretched yarn segment $l_{2}$ at axial force $f_{2}$

Figure 5: Mass invariance of yarn (Matthes, Pusch and Cherif, 2012) to deduce equations for true specific stress and true specific strain. 
Now,

True specific stress at tension $\mathrm{T}_{1}, \sigma_{\mathrm{T} 1}^{\prime}=\sigma_{\mathrm{T} 1}\left(1+\varepsilon_{\mathrm{T} 1}\right) \ldots . .(7)$

True specific stress at tension $\mathrm{T}_{2}, \sigma_{\mathrm{T} 2}^{\prime}=\sigma_{\mathrm{T} 2}\left(1+\varepsilon_{\mathrm{T} 2}\right) \ldots . .(8)$

Also

True specific strain at tension $\mathrm{T}_{1}, \varepsilon^{\prime} \mathrm{T} 1=\ln \left(1+\varepsilon_{\mathrm{T} 1}\right)$

True specific strain at tension $\mathrm{T}_{2}, \varepsilon^{\prime} \mathrm{T} 2=\ln \left(1+\varepsilon_{\mathrm{T} 2}\right)$

Considering Hooke's law it may be shown that

$$
\begin{aligned}
& \frac{\sigma_{T 1}^{\prime}}{\varepsilon_{T 1}^{\prime}}=\frac{\sigma_{T 2}^{\prime}}{\varepsilon_{T 2}^{\prime}} \\
& \Rightarrow \frac{\sigma_{T 1}\left(1+\varepsilon_{T 1}\right)}{\ln \left(1+\varepsilon_{T 1}\right)}=\frac{\sigma_{T 2}\left(1+\varepsilon_{T 2}\right)}{\ln \left(1+\varepsilon_{T 2}\right)} \\
& \Rightarrow \frac{\sigma_{T 1}\left(1+\frac{L_{T 1}-L_{0}}{L_{0}}\right)}{\ln \left(1+\frac{L_{T 1}-L_{0}}{L_{0}}\right)}=\frac{\sigma_{T 2}\left(1+\frac{L_{T 2}-L_{0}}{L_{0}}\right)}{\ln \left(1+\frac{L_{T 2}-L_{0}}{L_{0}}\right)} \\
& \Rightarrow \frac{\frac{T_{1}}{t} \times \frac{L_{T 1}}{L_{0}}}{\ln \frac{L_{T 1}}{L_{0}}}=\frac{\frac{T_{2}}{t} \times \frac{L_{T 2}}{L_{0}}}{\ln \frac{L_{T 2}}{L_{0}}} \\
& \Rightarrow \frac{T_{1} L_{T 1}}{t L_{0}} \times \ln \left(\frac{L_{T 2}}{L_{0}}\right)=\frac{T_{2} L_{T 2}}{t L_{0}} \times \ln \left(\frac{L_{T 1}}{L_{0}}\right) \\
& \Rightarrow \frac{T_{1} L_{T 1}}{t L_{0}} \times \ln \left(\frac{L_{T 2}}{L_{0}}\right)-\frac{T_{2} L_{T 2}}{t L_{0}} \times \ln \left(\frac{L_{T 1}}{L_{0}}\right)=0 \\
& \Rightarrow \frac{1}{t L_{0}}\left\{\mathrm{~T}_{1} L_{T 1} \ln \left(\frac{L_{T 2}}{L_{0}}\right)-\mathrm{T}_{2} L_{T 2} \ln \left(\frac{L_{T 1}}{L_{0}}\right)\right\}=0 \\
& \Rightarrow T_{1} L_{T 1} \ln \left(\frac{L_{T 2}}{L_{0}}\right)-T_{2} L_{T 2} \ln \left(\frac{L_{T 1}}{L_{0}}\right)=0 \\
& \Rightarrow \quad \ln \left(\frac{L_{T 2}}{L_{0}}\right)^{T_{1} L_{T 1}}-\ln \left(\frac{L_{T 1}}{L_{0}}\right)^{T_{2} L_{T 2}}=0 \\
& \Rightarrow \quad \ln \frac{\left(\frac{L_{T 2}}{L_{0}}\right)^{T_{1} L_{T 1}}}{\left(\frac{L_{T 1}}{L_{0}}\right)^{T_{2} L_{T 2}}}=0 \\
& \Rightarrow \quad \ln \left\{\left(\frac{L_{T 2}}{L_{0}}\right)^{T_{1} L_{T 1}}\left(\frac{L_{0}}{L_{T 1}}\right)^{T_{2} L_{T 2}}\right\}=0 \\
& \Rightarrow\left(\frac{L_{T 2}}{L_{0}}\right)^{T_{1} L_{T 1}}\left(\frac{L_{0}}{L_{T 1}}\right)^{T_{2} L_{T 2}}=1 \\
& \Rightarrow \frac{L_{T 2} T_{1} L_{T 1}}{L_{0} T_{1} L_{T 1}} \times \frac{L_{0} T_{2} L_{T 2}}{L_{T 1} T_{2} L_{T 2}}=1 \\
& \Rightarrow \quad L_{0}{ }^{T_{2} L_{T 2}-T_{1} L_{T 1}}=\frac{L_{T 1} T_{2} L_{T 2}}{L_{T 2} T_{1} L_{T 1}} \\
& \Rightarrow \quad L_{0}=\left(\frac{L_{T 1}{ }^{T_{2} L_{T 2}}}{L_{T 2}{ }^{T_{1} L_{T 1}}}\right)^{1 / T_{2} L_{T 2}-T_{1} L_{T 1}}
\end{aligned}
$$

By putting the values of $\mathrm{T}_{1}, \mathrm{~T}_{2}$ and corresponding $\mathrm{L}_{\mathrm{T} 1}$ and $\mathrm{L}_{\mathrm{T} 2}$ in Eqn.12 one can calculate actual course length that is expected in the produced fabric. 


\section{Experimental Verification of the Model Established: Experimental details}

In order to examine the validity of the model practical knitting outputs were compared with those predicted by the derived equation.

At first, Plain jersey fabric samples were knitted with same positive feed setting on a large diameter single jersey circular knitting machine (Orizio, Johnan) of 24 gauge and 26-inch Diameter having 1920 needles and 84 feeders. The yarns used were $14.90 \mathrm{Tex}(s=0.28)$ and $23.62 \mathrm{Tex}(s=0.40)$ Spun Polyester. Some mechanical properties of these yarns obtained through a CRE-type tester, are given in table 1. It is mentionable that if the elasticity curve is converted to a true specific stress- strain curve, linear relationship between stress and strain is also observed up to the proportional limit which is almost same to that of an engineering specific stress and strain curve.

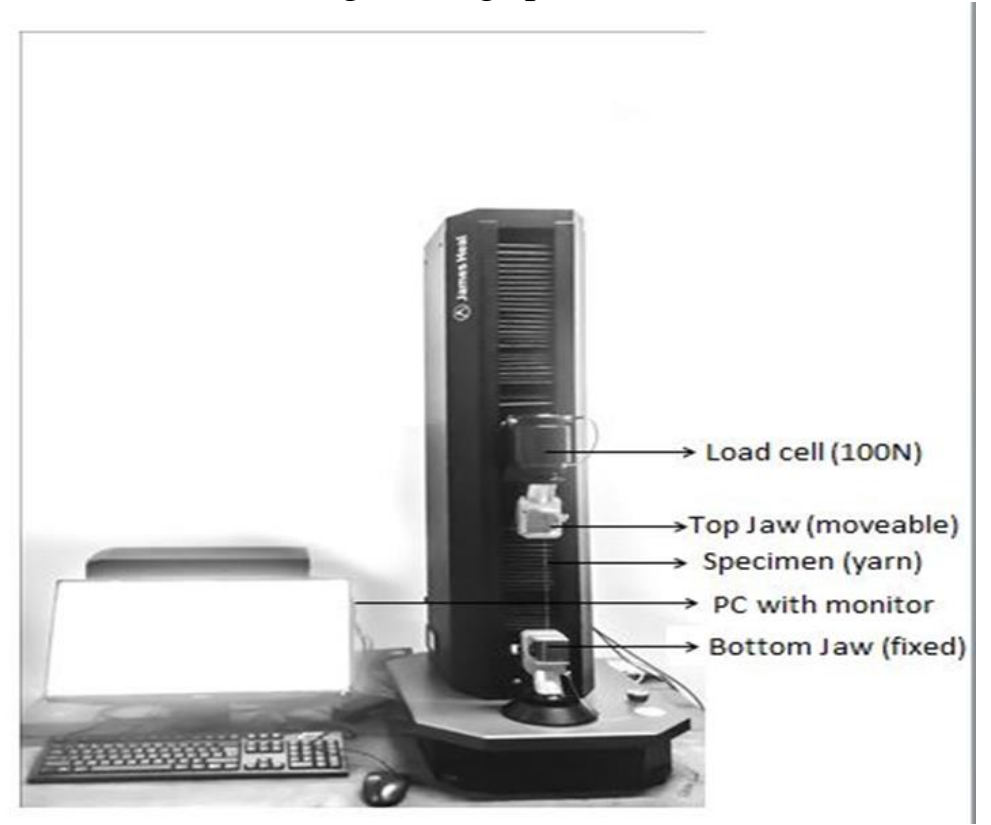

Figure 6: Test for tensile properties of yarn by Titan-Universal Strength Tester

Table 1: Mechanical properties of the experimental yarns obtained through TITAN universal Strength Tester

\begin{tabular}{|c|c|c|}
\hline $\begin{array}{c}\text { Yarn } \rightarrow \\
\text { Mechanical Property } \downarrow\end{array}$ & $\begin{array}{c}\text { Spun Polyester, } \\
17.90 \text { Tex }\end{array}$ & $\begin{array}{c}\text { Spun Polyester, } \\
\text { 23.62Tex }\end{array}$ \\
\hline Initial Modulus (cN/Tex) & $154 \quad(s=0.13)$ & $139(s=0.06)$ \\
\hline Tenacity (cN/Tex) & $13.69(s=1.19)$ & $13.77(s=0.62)$ \\
\hline Extension at break (\%) & $11.47(s=0.48)$ & $12.12(s=0.56)$ \\
\hline $\begin{array}{c}\text { Proportional Limit( as } \\
\text { force value, i.e. } \mathrm{cN})\end{array}$ & $30.62(s=2.72)$ & $48.50(s=2.54)$ \\
\hline
\end{tabular}


Knitting was performed at five couliering depths (cam settings) to obtain different yarn input tensions within the boundary of yarn's proportional limit keeping all other settings unchanged in identical environmental condition. MLT Wesco yarn tension and rate meter was used to get online reading for different tensions and corresponding yarn length/revolution of machine cylinder. (i.e. dynamic course length).

After knitting, all samples were dry relaxed statically. Loop lengths were then measured by unraveling yarns from fabric samples and then working on A HATRA Course Length Tester as per BS 5441:1988 (British Standards Institute, 1988) using a preload of $10 \mathrm{cN}$ as shown in table 2.

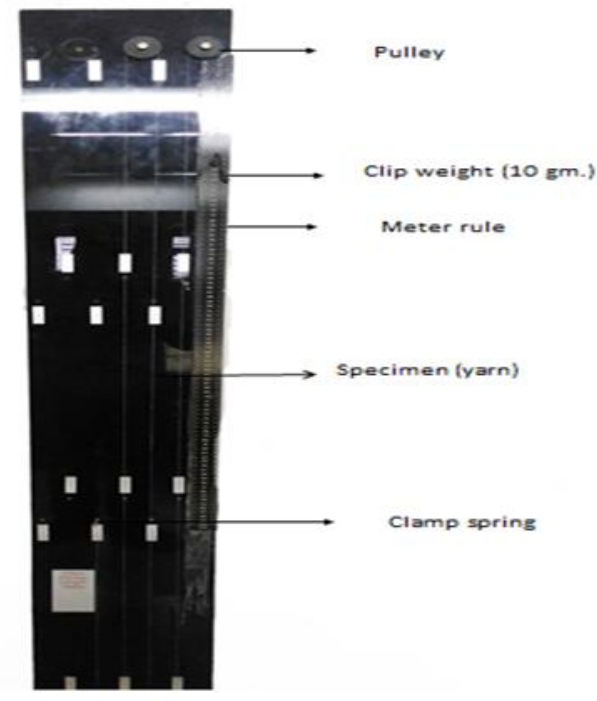

Figure 7: Course length measurement by HATRA course length tester.

The values of yarn length /cylinder revolution obtained through online measurements were used to predict actual course length by the model developed. A simple program was written through MATLAB (version 7.6.0.324-R2008a) for the said purpose. Table 3 shows the corresponding results.

Table 2: Course length determination by HATRA Course Length Tester from grey knitted fabric

\begin{tabular}{|c|c|c|}
\hline Reading No & $\begin{array}{c}\text { Course length measured from fabric } \\
\text { knitted with 17.90 Tex Spun } \\
\text { Polyester (m) }\end{array}$ & $\begin{array}{c}\text { Course length measured from } \\
\text { fabric knitted with 23.62 Tex Spun } \\
\text { Polyester (m) }\end{array}$ \\
\hline 1 & 5.2000 & 5.1900 \\
\hline 2 & 5.2050 & 5.1900 \\
\hline 3 & 5.2100 & 5.1950 \\
\hline 4 & 5.2100 & 5.2300 \\
\hline
\end{tabular}




\begin{tabular}{|c|c|c|}
\hline 5 & 5.2200 & 5.2050 \\
\hline 6 & 5.2250 & 5.2100 \\
\hline 7 & 5.2250 & 5.2150 \\
\hline 8 & 5.2200 & 5.2000 \\
\hline 9 & 5.2300 & 5.2100 \\
\hline 10 & 5.2300 & 5.1850 \\
\hline Average & 5.2175 & 5.2030 \\
\hline CV (\%) & 0.203 & 0.265 \\
\hline
\end{tabular}

Table 3: Predicted course length values as obtained through the evaluation of online measurements

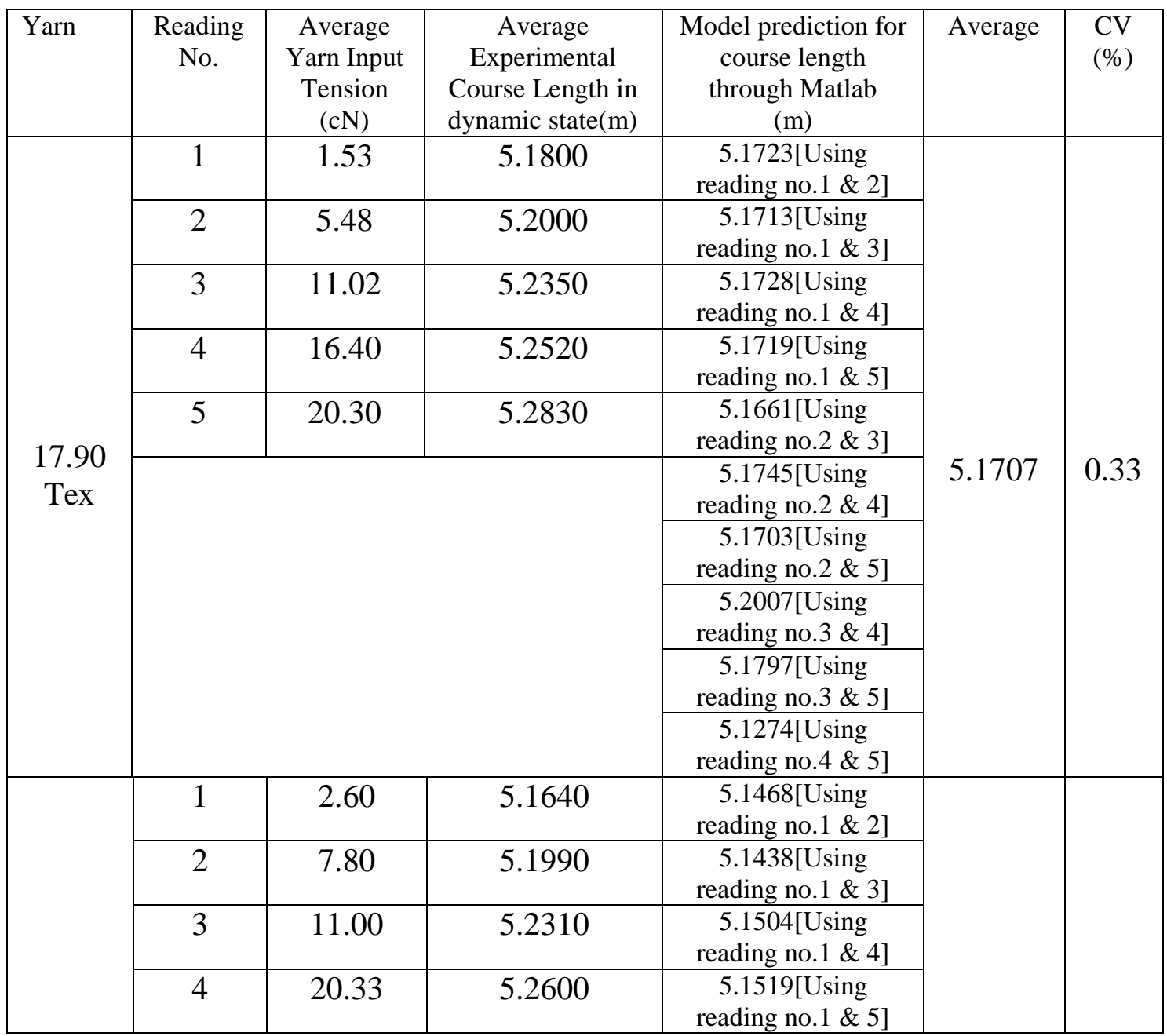




\begin{tabular}{|c|c|c|c|c|c|c|}
\hline \multirow{6}{*}{$\begin{array}{c}23.62 \\
\text { Tex }\end{array}$} & 5 & 27.58 & 5.2850 & $\begin{array}{c}5.1234[\mathrm{Using} \\
\text { reading no. } 2 \& 3 \text { ] }\end{array}$ & \multirow{6}{*}{5.163} & \multirow{6}{*}{0.48} \\
\hline & & & & $\begin{array}{c}5.1621[\text { Using } \\
\text { reading no. } 2 \& 4]\end{array}$ & & \\
\hline & & & & $\begin{array}{c}5.1662 \text { [Using } \\
\text { reading no.2 \& 5] }\end{array}$ & & \\
\hline & & & & $\begin{array}{c}5.1974[\text { Using } \\
\text { reading no.3 \& 4] }\end{array}$ & & \\
\hline & & & & $\begin{array}{c}.1961 \text { [Using } \\
\text { reading no.3 \& 5] }\end{array}$ & & \\
\hline & & & & $\begin{array}{c}5.1918[\mathrm{Using} \\
\text { reading no.4 \& 5] }\end{array}$ & & \\
\hline
\end{tabular}

\section{Results and discussion:}

Predicted loop length values obtained through the model and the actual course length values measured by HATRA Course Length Tester were compared using t-tests. Table 4, 5 and 6 shows the corresponding results.

Table 4: Results of t-test of predicted course length values through model and actual course length values for fabric knitted with 17.90 Tex Spun Polyester.

\begin{tabular}{|c|c|c|}
\hline $\begin{array}{c}\text { Statistical parameters for a } \\
\text { two samples t-test } \\
\text { assuming equal variance }\end{array}$ & Model prediction & $\begin{array}{c}\text { HATRA Course Length } \\
\text { Tester Measurement }\end{array}$ \\
\hline No. of observations & 10 & 5.2175 \\
\hline Mean & 5.1707 & 0.0001125 \\
\hline Mean Difference & 0.000290042 & 0.0468 \\
\hline Variance & \multicolumn{2}{|c|}{5.31080014} \\
\hline t-Value & \multicolumn{2}{|c|}{0.00000128943} \\
\hline p-value &
\end{tabular}

Table 5: Results of t-test of predicted course length values through model and actual course length values for fabric knitted with 23.62Tex Spun Polyester

\begin{tabular}{|c|c|c|}
\hline $\begin{array}{c}\text { Statistical parameters } \\
\text { for a two samples t-test } \\
\text { assuming equal variance }\end{array}$ & Model prediction & $\begin{array}{c}\text { HATRA Course Length } \\
\text { Tester Measurement }\end{array}$ \\
\hline No. of observations & 10 & 10 \\
\hline Mean & 5.163 & 5.203 \\
\hline Mean Difference & 0.000622297 & 0.040 \\
\hline Variance & \multicolumn{2}{|c|}{3.192661075} \\
\hline t-Value & \multicolumn{3}{|c|}{0.000316741} \\
\hline p-value &
\end{tabular}


Table 6: Results of t-test of course length values measured through HATRA apparatus for fabric knitted with 17.90Tex Spun Polyester and 23.62Tex Spun Polyester yarns

\begin{tabular}{|c|c|c|}
\hline $\begin{array}{c}\text { Statistical parameters for } \\
\text { a two samples t-test } \\
\text { assuming equal variance }\end{array}$ & $\begin{array}{c}\text { HATRA Course Length } \\
\text { Tester Measurement for } \\
\text { Course lengths from fabrics } \\
\text { knitted with 17.90 Tex Spun } \\
\text { Polyester }\end{array}$ & $\begin{array}{c}\text { HATRA Course Length } \\
\text { Tester Measurement for } \\
\text { Course lengths from fabrics } \\
\text { knitted with 23.62 Tex Spun } \\
\text { Polyester }\end{array}$ \\
\hline No. of observations & 10 & 10 \\
\hline Mean & 5.2175 & 5.203 \\
\hline Mean Difference & 0.0001125 & 0.00019 \\
\hline Variance & \multicolumn{2}{|c|}{1.902640666} \\
\hline t-Value & \multicolumn{2}{|c|}{0.016764792} \\
\hline p-value & \multicolumn{2}{|c}{} \\
\hline
\end{tabular}

From table 4 and 5 it can be found that the average course length values predicted by the model is always smaller than that found actually in fabric by the HATRA Course Length Tester. The obtained t-values reject the null hypothesis and indicates that there is a statistically significant difference between the outcomes obtained through the model and the HATRA Course Length Tester based on the 95\% confidence level ( $p$-value $=0.00000128943$ for table 4 and $p$-value $=0.000316741$ for table 5). The differences between the predicted course lengths and the HATRA findings will result a variation of around $0.02 \mathrm{~mm}$ in stitch length on the produced fabric (as found from the mean differences in course lengths of 0.0468 meter for table 4 and 0.040 meter for table 5).The reason for such difference may be well understood if we examine the change in the mechanical property of the yarn after the knitting process as shown in figure 8 .

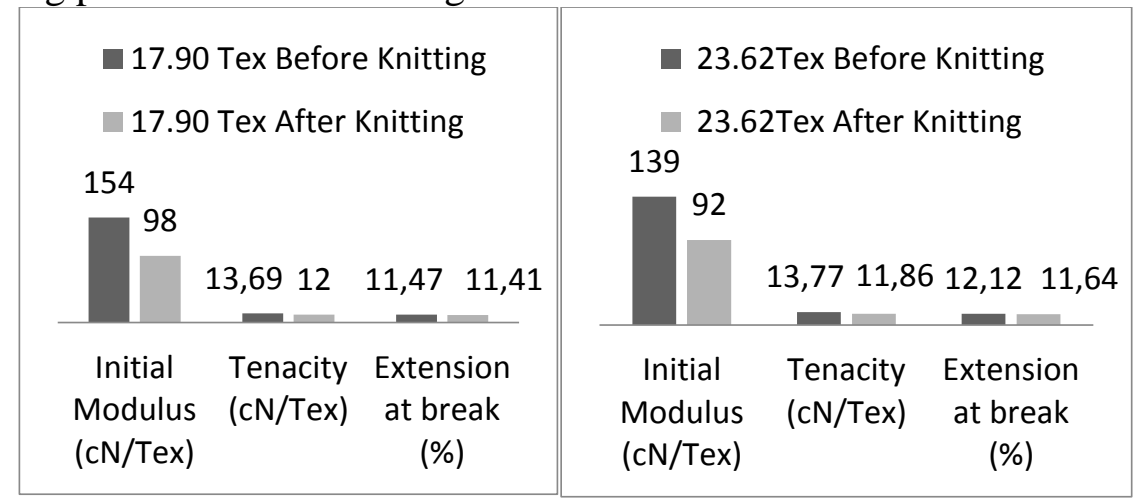

Figure8: Comparison between some mechanical properties of spun polyester yarns (obtained by Titan Universal Strength Tester, ASTM D2256-10(2015) (American Society for Testing and Materials, 2015), gauge length $=250 \mathrm{~mm}$, speed $=90 \mathrm{~mm} / \mathrm{min}$ ) as found before knitting and as found after knitting .i.e. yarn from the knitted fabric.

Yarn, assuming that any permanent deformation has not occurred may suffer from local microfractures when subjected to variable stress, even 
if its maximum value does not exceed the yield point (Włochowicz, Kukla, \& Drobina, 2016). According to Jurasz's 2003 stuy( as cited in Włochowicz, Kukla, \& Drobina, 2016), the internal destruction of threads changes the modulus of yarn. Inside the knitting zone yarn experiences variable stress as well as frictional drag by knitting elements like needles and sinkers, which are mainly responsible for significant reduction in yarn modulus. Due to this reason it is not surprising that yarn may have stretched considerably after straightening on the application of preload of $10 \mathrm{cN}$ while measuring course length through HATRA instrument resulting positive deviation from that predicted values through the equation. Little and Heapworth (1977) also expressed similar opinion over such type of extension.

Table 6 represents the comparison of two sets of observations found through the HATRA course Length Tester. The $t$-value of 1.90264040666 with the corresponding p-value of 0.016764792 indicate no significant difference based on the $95 \%$ confidence level between the course length values measured for fabrics knitted with 17.90 Tex spun polyester and fabrics knitted with 23.62 tex spun polyester by HATRA instrument with the recommended preload of $10 \mathrm{cN}$. The mean difference for course lengths of 0.0145 meter results no mentionable difference in stitch length. So it can be concluded that yarn linear density shows almost no effect on course length.

Though this was found for spun polyester but it is expected to be true for other yarns if the values are maintained within the specified range for same machine setting and off-machine measurements are carried out through HATRA course Length Tester at defined preload.

\section{Conclusion}

An attempt has been carried out through this work to derive a model for prediction of actual course length in grey knitted fabric from online reading of yarn tensile force and yarn delivery: a defined simple equation for yarn length consumption per cylinder revolution in case of positive storage feeding. Applying the mathematical relation, instantaneous calculation of fabric loop length is basically possible for any yarn, whether it has high or low modulus. By comparing the model predicted values with those measured from the original fabric by a Course Length Tester it was found that a very good agreement exists with little difference in resultant stitch length.

The present study on spun polyester knitted fabric with two different counts showed that calculated loop length from the dynamic yarn tension and course length is somewhat smaller than that measured actually from the fabric by less than $1 \%$, which translates a lesser stitch length of $0.02 \mathrm{~mm}$. To allow the application of the developed model in industrial manufacturing process for different yarns and knitting conditions, numerical findings 
obtained through some preproduction samples must be evaluated independently for statistical significance before bulk production.

\section{Acknowledgement}

The authors are grateful to the Department of Mechanical Engineering of Bangladesh University of Engineering and Technology for sponsoring the work and to Padma PolyCotton Knit Fabrics Limited, Dhaka for providing the research facilities. Special thanks are extended to the Department of Textile Engineering of Ahsanullah University of Science and Technology for their cooperation.

\section{References:}

1. Abou-iiana, M. (2000). Dynamic Knitting Tension. Knit. Technol, 2(3), 18-19.

2. Adanur, S. Wellington Sears handbook of industrial textiles. 1995. Technomic Pub.: Lancaster, Pa., 575.

3. American Society for Testing and Materials (2015) .ASTM D225610(2015): Standard Test Method for Tensile Properties of Yarns by the Single-Strand Method.USA:ASTM International.

4. Booth, J. E. (1961). Principles of textile testing: an introduction to physical methods of testing textile fibres, yarns and fabrics (3rd ed), Butterworths , 268.

5. British Standards Institute (1988). BS 5441:1988-Methods of test for knitted fabrics.UK:BSI

6. Catarino, A., Rocha, A., Monteiro, J. L., \& Soares, F. (2004, June). A new system for monitoring and analysis of the knitting process. In Mechatronics, 2004. ICM'04. Proceedings of the IEEE International Conference on (pp. 415-420). IEEE.

7. Dias, T., \& Lanarolle, G. (2002). Stitch length variation in circular knitting machines due to yarn winding tension variation in the storage yarn feed wheel. Textile research journal, 72(11), 997-1001.

8. Goswami, B. C., Martindale, J. G., \& Scardino, F. L. (1977). Textile yarns; Technology, structure, and applications. John Wiley and Sons, 1 .

9. Hossain A.K.M.M., Hoque S. N.(2013) Influence on Dimensional Changes of Cotton Plain Single Jersey Weft Knitted Fabric at Different Relaxed States Due to the Variation of Knitting Parameters. The AUST Journal of Science and Technology, 5(2), 29-42.

10. Little, T. J., \& Hepworth, A. (1977). The determination of fabric loop length. Textile Research Journal, 47(12), 795-801. 
11. Matthes, A., Pusch, T., \& Cherif, C. (2012). Numerical simulation of yarn tensile force for dynamic yarn supply systems of textile machines. Journal of the Textile Institute, 103(1), 70-79.

12. Mishra, S. P. (2000). A text book of fibre science and technology. New Age International, 334.

13. Pavko-Cuden, A., \& Sluga, F. (2015). Measuring loop lengths of elasticised knitted fabrics. The Journal of The Textile Institute, 106(3), 225-235

14. Ray S. C (2013). Process control in knitting. In A Majumdar, A Das, R. Alagirusamy and V. K. Kothari (eds), Process control in textile manufacturing. Woodhead Publishing Limited, 252.

15. Saville, B. P. (1999). Physical testing of textiles. Elsevier,116-117

16. Włochowicz, A., Kukla, S., \& Drobina, R. (2016). Static and Fatigue Strength of Linear Textile Products. Fibres \& Textiles in Eastern Europe, 3(117), 8-16 